Article

\title{
Association of Dietary Pattern, Lifestyle and Chronotype with Metabolic Syndrome in Elderly-Lessons from the Population-Based Hamburg City Health Study
}

\author{
Claudia Terschüren ${ }^{1}$ * , Lukas Damerau ${ }^{1}$, Elina Larissa Petersen ${ }^{2,3}{ }^{\mathbb{D}}$, Volker Harth ${ }^{1}$, Matthias Augustin ${ }^{4}$ \\ and Birgit-Christiane Zyriax ${ }^{5, *(D)}$
}

1 Institute for Occupational and Maritime Medicine (ZfAM), University Medical Center Hamburg-Eppendorf (UKE), 20459 Hamburg, Germany; l.damerau@uke.de (L.D.); harth@uke.de (V.H.)

2 Department of Cardiology, University Heart and Vascular Center, 20251 Hamburg, Germany; e.petersen@uke.de

3 Population Health Research Department, University Heart and Vascular Center, 20251 Hamburg, Germany

4 Competence Center for Health Services Research in Vascular Diseases (CVvasc), Institute for Health Service Research in Dermatology and Nursing (IVDP), University Medical Centre Hamburg-Eppendorf (UKE), 20246 Hamburg, Germany; m.augustin@uke.de

5 Midwifery Science-Health Services Research and Prevention, Institute for Health Service Research in Dermatology and Nursing (IVDP), University Medical Centre Hamburg-Eppendorf (UKE), 20246 Hamburg, Germany

* Correspondence: c.terschueren@uke.de (C.T.); b.zyriax@uke.de (B.-C.Z.); Tel.: +49-(0)4042837-4326 (C.T.); +49-(0)4074105-3947 (B.-C.Z.)

check for

updates

Citation: Terschüren, C.; Damerau,

L.; Petersen, E.L.; Harth, V.; Augustin,

M.; Zyriax, B.-C. Association of

Dietary Pattern, Lifestyle and

Chronotype with Metabolic

Syndrome in Elderly-Lessons from

the Population-Based Hamburg City

Health Study. Int. J. Environ. Res.

Public Health 2022, 19, 377. https://

doi.org/10.3390/ijerph19010377

Academic Editor: Paul B. Tchounwou

Received: 3 November 2021

Accepted: 22 December 2021

Published: 30 December 2021

Publisher's Note: MDPI stays neutral with regard to jurisdictional claims in published maps and institutional affiliations.

Copyright: (C) 2021 by the authors. Licensee MDPI, Basel, Switzerland. This article is an open access article distributed under the terms and conditions of the Creative Commons Attribution (CC BY) license (https:// creativecommons.org/licenses/by/ $4.0 /)$.

\begin{abstract}
In aging populations, the increasing prevalence of metabolic syndrome and the resulting elevated risk of developing non-communicable diseases is a major challenge for worldwide health care. The elderly population-based Hamburg City Health Study (HCHS) allows investigating the association in the relevant age group 45-74 years. For 3513 of 10,000 participants, self-reported information on dietary patterns (DASH, MEDAS), chronotype, lifestyle, and data on metabolic syndrome parameters was available. Overall, having a "low" DASH score was a statistically significant risk factor (OR 1.23; 95\% CI 1.01-1.48). Only for "late" chronotype, a slightly elevated OR (1.06) was found, but no statistically significant effect on the outcome of metabolic syndrome. Still, considering chronotype vastly improved the model. However, a trend of an increasing predicted probability from early to late chronotype was found for participants with low adherence to the DASH diet. Future research should focus on options for prevention in persons with late chronotype, so they can be supported better in adherence to, e.g., DASH diet to lower their risk.
\end{abstract}

Keywords: metabolic syndrome; chronotype; diet; DASH; cohort; elderly

\section{Introduction}

The metabolic syndrome (MetS) is associated with a higher risk of non-communicable diseases like nonalcoholic fatty liver disease (NAFLD), cardiovascular disease (CVD), and several types of cancer. According to the International Diabetes Federation (IDF), MetS is defined as a cluster of abdominal adiposity, glucose intolerance, increased blood pressure, and dyslipidemia [1]. Due to the increased number of comorbidities and physiological changes that develop at older ages-such as an increase in the percentage of body fat and decrease in muscle mass [2], older adults are particularly at risk of developing MetS.

In Germany, the Study of Health in Pomerania (SHIP) showed an overall prevalence of $23.8 \%$ (women: $18.6 \%$; men: $29.1 \%$ ) of MetS in the adult population [3]. In the youngest age group (20 to 29 years), the prevalence was $4.0 \%$ in women and $6.6 \%$ in men, whereas in the age group of 70 years and older, $44.7 \%$ of the women and $39.8 \%$ of the men met the criteria for MetS. Referring to these results, almost half of the older population is developing MetS. 
In Germany, trends by age and educational status (ES) are observed for single parameters that compose the MetS. The German nationwide survey GEDA 2014/2015-EHIS showed a 12-month-prevalence of diabetes mellitus type 2 of $7.7 \%$ in adults (18 years and older) [4]. In women, the prevalence was lower ( $7.0 \%)$ than in men $(8.6 \%)$, based on 23,345 participants [4]. For women aged 45 to 64 years of age, a prevalence of $5.2 \%$ (men: 9.3\%) was found; in women older than 65 years, a prevalence of $17.6 \%$ (men: $21.1 \%$ ) was observed. Women older than 65 with a low ES more often reported type 2 diabetes (12-month-prevalence: $20.5 \%$ ) compared to women of the same age with a high ES (15.9\%). In men, a similar difference was observed (ES low: 24.0\%; ES high: 19.4\%). The same trends were found for increased blood pressure in the GEDA survey 2014/2015 and for dyslipidemia in the DEGS 2010 [5]. The 12-month-prevalence of high blood pressure increased by age (45 to 65: women 31.6\%; men 38.6\% vs. 65 older: women $63.8 \%$; men $65.1 \%$ ) and differed by ES (high: women $58.0 \%$; men $64.5 \%$ vs. low ES: women $66.4 \%$; men $65.5 \%$ ). As to dyslipidemia, the 12-month-prevalence increased by age and particularly in women (45 to 65: women: $21.5 .7 \%$; men: $27.2 \%$ vs. 65 older: women $41.2 \%$; men $39.5 \%$ ). The age effect is even stronger when considering the ES.

In light of the demographic changes and deficits in health literacy, better prevention concepts concerning healthy aging are highly important. Dietary habits and physical activity are well-known factors in the development of MetS [6]. Different aspects of dietary pattern, including energy intake, macronutrient composition, fiber intake, and food pattern, seem to influence the prevalence of MetS and its clustered individual parameters [7]. According to a recent comprehensive review, scientific evidence supports the use of a "Dietary Approaches to Stop Hypertension (DASH)" diet intervention as the paradigm for MetS prevention and treatment [7]. Small dietary changes rather than the restriction of single nutrients are seen to be protective. On top of that, the emerging roles of circadian rhythms and sleep influencing food and nutrient intake should be considered and may act as modifying factors.

Further research is needed to investigate if chronotype modifies the association between food intake, dietary patterns, and MetS [8]. Suh et al. (2017) [9] found that older adults with an evening chronotype consume more caffeinated beverages plus eat heavier meals at night before sleeping. Other studies found that evening chronotypes showed a lower adherence toward a healthy Nordic diet, were more often physically inactive, and reported lower perceived health [10]. In the National FINRISK 2007 Study population, participants who were evening type consumed more fat and less vitamin D, and they showed a higher intake of alcohol and sucrose [11]. Patterson et al. (2016) observed similar habits in late chronotypes. They consumed, on average, fewer daily servings of fruits and vegetables than other early or intermediate chronotypes [12]. The recent scoping review of Mazri et al. (2020) on chronotype and dietary patterns among adults confirms these findings for evening-type individuals based on an evaluation of 29 studies, mostly executed in a cross-sectional design [13].

A recent review of Almoosawi et al. (2019) stated that chronotype might modulate physiologic processes linked to cardiovascular health, including heart rate, blood pressure, and blood lipid concentrations. The authors also reason that chronotype may affect dietary intake and eating patterns, which might result in disturbed glucose metabolism, and in the long term, promotes type 2 diabetes and MetS [8]. Roenneberg et al. (2012) found that sleep duration and living against the inner clock increases BMI in overweight persons [14]. In older age, during retirement, sleeping habits on weekdays and free weekends became more alike, and chronotype in average changes into more early types.

The population-based Hamburg City Health Study (HCHS) focuses on the age group 45 to 74 years [15]. Thus, this mid-aged and elderly study population allows one to investigate the association of diet, eating pattern, chronotype, lifestyle, and MetS in the relevant age group. The MetS emerges predominantly and consolidates in the persons affected. With this analysis, we want to investigate if taking the chronotype into account 
might provide a possible approach in the prevention of MetS and in reducing sequelae like stroke, infarction, or diabetes mellitus type 2 in the elderly.

\section{Materials and Methods}

\subsection{Study Population}

This study is embedded in the ongoing "Hamburg City Health Study" (HCHS). The HCHS aims to build a cohort of finally 45,000 population-based participants in Hamburg (Jagodzinski et al., 2020) [15]. Eligible were individuals from 45 to 74 years of age at time of sampling and lived in Hamburg, Germany. Potential participants were randomly invited via the registration office. They received a letter with the data protection declaration and the first questionnaire. Later, they were invited to the University Medical Center Hamburg-Eppendorf (UKE) if their language skills were sufficient to comprehend the questionnaires and instructions from the study personnel and able to participate in the medical examinations. All participants gave written informed consent. Participants' data of this study were extracted from the dataset of the first sub-cohort HCHS $(n=10,000)$. Data for this sub-cohort was collected between 2016 and 2019.

For this analysis, needed data was available for 4330 of 10,000 participants. Those with a prior history of heart attacks, strokes, and illnesses associated with the coronary vessels were excluded $(n=358)$ due to the potential confounder risk in association with the outcome variable MetS.

Margin age groups, which were disproportionally underrepresented in HCHS compared to the reference population of the City of Hamburg, were excluded to reduce bias. The final sample size enclosed in this analysis amounts to $n=3513$.

\subsection{Outcome Variable-MetS}

The outcome MetS was based on the definition of the IDF [1]. Height, weight, waist circumference, and blood pressure were measured by trained study nurses at the HCHS study center, and blood samples were taken. Participants were asked to bring their medication packages, so their medication's specific product codes (PZN, "Pharmazentralnummer", a unique German barcode identifier for medicinal products) could be scanned. That allowed to determine whether the participants used a drug associated with parameters of the MetS.

To assign the status of MetS according to IDF, participants had to be abdominal adipose (waist circumference of $>94 \mathrm{~cm}$ in men and of $>80 \mathrm{~cm}$ in women). Additionally, at least 2 of the 4 following conditions must be fulfilled:

1. Raised triglycerides $\geq 150 \mathrm{mg} / \mathrm{dL}$ or specific medication for this lipid abnormality.

2. Reduced HDL cholesterol (men $<40 \mathrm{mg} / \mathrm{dL}$, women $<50 \mathrm{mg} / \mathrm{dL}$ ) or specific medication for this lipid abnormality/

3. Raised blood pressure exceeds $\geq 130 \mathrm{~mm} \mathrm{Hg}$ systolic or $\geq 85 \mathrm{~mm} \mathrm{Hg}$ diastolic or medication of the previously diagnosed hypertension.

4. Raised fasting plasma glucose $\geq 100 \mathrm{mg} / \mathrm{dL}$ or previously diagnosed type 2 diabetes mellitus.

\subsection{Dietary Scores}

Information on dietary intake was collected by validated questionnaires developed for the European Prospective Investigation into Cancer and Nutrition (EPIC) study [16]. The used dietary questionnaire (food frequency questionnaire, version 2 (FFQ2)) records the frequency and portion size of 102 food items eaten during the previous year [16]. Relevant food groups, energy intake, and nutrients were assessed.

Dietary Approaches to Stop Hypertension (DASH) To calculate adherence to the DASH diet, a scoring scheme from Folsom et al. (2007) was used [17]. The overall score included 10 equally weighted food items (frequency consumption of grains, vegetables, fruits, dairy, meat/poultry/fish, nuts/seeds/legumes, sweets obtained from raw data) and average daily intakes of certain nutrients (fat, saturated fat, sodium) (Table 1). A score of $0-1$ was assigned for each dietary component and summed across the 10 items [18]. A score of 10 reflected full adherence, while 0 represented non-adherence. 
Table 1. Scoring criteria for DASH Dietary Adherence.

\begin{tabular}{|c|c|c|}
\hline Score Items & DASH Component & Scoring \\
\hline 1 & $\begin{array}{c}\text { Total Grain } \\
\geq 7 \text { servings/day } \\
5-6 \text { servings/day } \\
<5 \text { servings/day }\end{array}$ & $\begin{array}{c}1 \\
0.5 \\
0\end{array}$ \\
\hline 2 & $\begin{array}{c}\text { Vegetables } \\
\geq 4 \text { servings/day } \\
2-3 \text { servings/day } \\
<2 \text { servings/day }\end{array}$ & $\begin{array}{c}1 \\
0.5 \\
0\end{array}$ \\
\hline 3 & $\begin{array}{l}\text { Fruits } \\
\geq 4 \text { servings/day } \\
2-3 \text { servings/day } \\
<2 \text { servings/day }\end{array}$ & $\begin{array}{c}1 \\
0.5 \\
0\end{array}$ \\
\hline 4 & $\begin{array}{c}\text { Total dairy } \\
\geq 2 \text { servings/day } \\
1 \text { servings/day } \\
<1 \text { serving/day }\end{array}$ & $\begin{array}{c}1 \\
0.5 \\
0\end{array}$ \\
\hline 5 & $\begin{array}{l}\text { Meat, poultry, and fish } \\
\leq 2 \text { servings/day } \\
3 \text { servings/day } \\
\geq 4 \text { serving/day }\end{array}$ & $\begin{array}{c}1 \\
0.5 \\
0\end{array}$ \\
\hline 6 & $\begin{array}{c}\text { Nuts, seeds, and legumes } \\
\geq 4 \text { servings/day } \\
2-3 \text { servings/day } \\
<2 \text { servings/day }\end{array}$ & $\begin{array}{c}1 \\
0.5 \\
0\end{array}$ \\
\hline 7 & $\begin{array}{c}\% \text { kcal from fat } \\
\leq 27 \% \\
\geq 28 \leq 29 \% \\
\geq 30 \%\end{array}$ & $\begin{array}{c}1 \\
0.5 \\
0\end{array}$ \\
\hline 8 & $\begin{array}{c}\% \text { kcal from saturated fat } \\
\leq 6 \% \\
\leq 7 \geq 8 \% \\
\geq 9 \%\end{array}$ & $\begin{array}{c}1 \\
0.5 \\
0\end{array}$ \\
\hline 9 & $\begin{array}{c}\text { Sweets } \\
\leq 5 \text { servings/week } \\
6-7 \text { servings/week } \\
\geq 8 \text { serving/week }\end{array}$ & $\begin{array}{c}1 \\
0.5 \\
0\end{array}$ \\
\hline 10 & $\begin{array}{c}\text { Sodium } \\
\leq 2400 \mathrm{mg} / \text { day } \\
2400-3000 \mathrm{mg} / \text { day } \\
>3000 \mathrm{mg} / \text { day }\end{array}$ & $\begin{array}{c}1 \\
0.5 \\
0\end{array}$ \\
\hline
\end{tabular}

Mediterranean Diet Adherence Screener (MEDAS) To assess adherence to the Mediterranean diet, the validated German translation of the original MEDAS was used [19]. The MEDAS score is based on 12 questions on food items (frequency consumption of food groups by using raw data, mean daily intake of vegetable oil and animal fat) and 2 questions on food intake habits characteristic of the Mediterranean diet.

Each item was scored with a 0 (condition not met) or a 1 (adherent); thus, the MEDAS score ranged from 0 to 14 points (Appendix A Table A1). The MEDAS scores of the participants were then transformed into tertiles, resulting in three equally sized groups as "low", "medium", and "high". 


\subsection{Chronotype}

Individual sleeping habits were ascertained based on the "Munich Chronotype Questionnaire" [20]. The chronotype was calculated for work-free days. Exclusion criteria were the use of alarm clock, dependent sleep cycle (due to, e.g., care for family members), implausible total sleep duration of fewer than $3 \mathrm{~h}$ or more than $15 \mathrm{~h}$, or missing values in sleep onset or wake-up time. Due to quality assurance measures, implausible values $(n=100)$ were corrected, e.g., if persons obviously mixed up the 24-h system and time in a.m./p.m. "Normal" chronotypes had rounded to half an hour mid-sleeps between 04:00 and 04:30, early between 03:30 and 23:00, and late between 05:00 and 10:00.

\subsection{Covariates}

To assess physical activity, participants completed the European Prospective Investigation into Cancer and Nutrition Physical Activity Questionnaire (EPIC-PAQ) [21]. The activity was assessed separately for summer and winter. Time was cumulated and divided by two to receive a proxy for the year's weekly average in total. This was transferred into a variable dichotomizing equal to or more than $1 \mathrm{~h} /$ week (reference) and less than $1 \mathrm{~h} /$ week.

The smoking status was queried during the anamnesis at the study center. The analysis included smoking status using three levels: never smoker, ex-smoker for at least six months, and current smoker.

As a proxy for socioeconomic status, the highest level of school-leaving qualification was included in data analysis (divided into three groups "high", "medium," and "low").

\subsection{Statistical Analyses}

Binary logistic regression was used to determine the risk factors of the independent variables age, sex, sport, educational level, smoking status, and DASH diet to the dependent outcome variable: MetS (risk estimates with a 95\% confidence interval). Each variable in the regression model was tested for interaction. A $p$-value of $<0.05$ was considered statistically significant. Statistical analyses were done using R 3.6.2 (R Development Core Team, Auckland, New Zealand).

\section{Results}

\subsection{Study Sample}

The final sample size consisted of $n=3513$ complete-case participants. In Table 2, the characteristics of the participants are shown (women: $50.4 \%$, men: $49.6 \%$ ). The average age was 61.4 years (SD 6.8, range 50 to 74). Men reported more often a high education level ("high") according to their school diploma (high education: $48.3 \%$ in women, $58.5 \%$ in men). Women and men almost equally often were "current-smoker," but women reported more often to be "never-smoker" (women: $40.1 \%$ vs. men: $33.7 \%$ ).

Table 2. Baseline characteristics of the study population.

\begin{tabular}{cccc}
\hline & Women & Men & Total \\
\hline$n(\%)$ & $2070(47.8 \%)$ & $2260(52.2 \%)$ & $4330(100 \%)$ \\
\hline Diagnosis heart attack, $n(\%)$ & $19(0.9 \%)$ & $101(4.5 \%)$ & $120(2.8 \%)$ \\
Diagnosis stroke, $n(\%)$ & $42(2.0 \%)$ & $71(3.1 \%)$ & $113(2.6 \%)$ \\
Diagnosis coronary heart disease, $n(\%)$ & $32(1.6 \%)$ & $178(8.0 \%)$ & $210(4.9 \%)$ \\
\hline At least one with diagnosis and thus excluded & $81(100.0 \%)$ & $277(100.0 \%)$ & $358(100.0 \%)$ \\
\hline Also excluded by age & $137(6.9 \%)$ & $290(7.3 \%)$ \\
\hline $45-49$ years & $153(7.7 \%)$ & $169(4.3 \%)$ \\
\hline $75+$ years & $64(3.2 \%)$ & $105(5.3 \%)$ \\
\hline After exclusion due to prior history of relevant illnesses and age \\
\hline$n(\%)$ & $1772(50.4 \%)$ & $1741(49.6 \%)$ & $3513(100 \%)$ \\
\hline
\end{tabular}


Table 2. Cont.

\begin{tabular}{|c|c|c|c|}
\hline & Women & Men & Total \\
\hline Age years, mean (SD) & $61.1(6.707)$ & $61.799(6.8)$ & $61.4(6.777)$ \\
\hline \multicolumn{4}{|l|}{ Age categories, $n(\%)$} \\
\hline $50-54$ & $368(20.8 \%)$ & $326(18.7 \%)$ & $694(19.8 \%)$ \\
\hline $55-59$ & $424(23.9 \%)$ & $358(20.6 \%)$ & $782(22.3 \%)$ \\
\hline $60-64$ & $401(22.6 \%)$ & $388(22.3 \%)$ & $789(22.5 \%)$ \\
\hline $65-69$ & $341(19.2 \%)$ & $399(22.9 \%)$ & $740(21.1 \%)$ \\
\hline $70-74$ & $238(13.4 \%)$ & $270(15.5 \%)$ & $508(14.5 \%)$ \\
\hline Age $\geq 65$ years, $n(\%)$ & $579(32.7 \%)$ & $669(38.4 \%)$ & $1248(35.5 \%)$ \\
\hline Sport $\geq 1 \mathrm{~h} /$ week, $n(\%)$ & $1326(74.8 \%)$ & $1165(66.9 \%)$ & $2491(70.9 \%)$ \\
\hline \multicolumn{4}{|l|}{ School diploma, $n(\%)$} \\
\hline low & $331(18.7 \%)$ & $315(18.1 \%)$ & $646(18.4 \%)$ \\
\hline medium & $586(33.1 \%)$ & $408(23.4 \%)$ & $994(28.3 \%)$ \\
\hline high & $855(48.3 \%)$ & $1018(58.5 \%)$ & $1873(53.3 \%)$ \\
\hline \multicolumn{4}{|l|}{ Smoking status, $n(\%)$} \\
\hline Never-smoker & $711(40.1 \%)$ & $587(33.7 \%)$ & $1298(36.9 \%)$ \\
\hline Ex-smoker & $735(41.5 \%)$ & $820(47.1 \%)$ & $1555(44.3 \%)$ \\
\hline Smoker & $326(18.4 \%)$ & $334(19.2 \%)$ & $660(18.8 \%)$ \\
\hline BMI, mean (SD) & $26.0(4.8)$ & $27.0(4.2)$ & $26.5(4.5)$ \\
\hline \multicolumn{4}{|l|}{ BMI category, $n(\%)$} \\
\hline Normalweight (BMI 18.5-24.9) & $841(32.0 \%)$ & $557(32.0 \%)$ & $1398(39.8 \%)$ \\
\hline Undeweight $(\mathrm{BMI}<18.5)$ & $30(1.7 \%)$ & $5(0.3 \%)$ & $35(1.0 \%)$ \\
\hline Overweight BMI (25-29.9) & $599(33.8 \%)$ & $843(48.4 \%)$ & $1442(41.0 \%)$ \\
\hline Adipose $(\mathrm{BMI} \geq 30)$ & $302(17.0 \%)$ & $336(19.3 \%)$ & $638(18.2 \%)$ \\
\hline \multicolumn{4}{|l|}{ Sleeptime in $\mathrm{h}, n(\%)$} \\
\hline 6-8 & $999(56.4 \%)$ & $1024(58.8 \%)$ & $2023(57.6 \%)$ \\
\hline$<6$ & $141(8.0 \%)$ & $115(6.6 \%)$ & $256(7.3 \%)$ \\
\hline$>8$ & $632(35.7 \%)$ & $602(34.6 \%)$ & $1234(35.1 \%)$ \\
\hline \multicolumn{4}{|l|}{ Chorotype, $n(\%)$} \\
\hline "normal" & $808(45.6 \%)$ & $740(42.5 \%)$ & $1548(44.1 \%)$ \\
\hline early & $514(29.0 \%)$ & $496(28.5 \%)$ & $1010(28.8 \%)$ \\
\hline late & $450(25.4 \%)$ & $505(29.0 \%)$ & $955(27.2 \%)$ \\
\hline Energy intake kcal/day, mean (SD) & $\begin{array}{l}1843.4 \\
(572.5)\end{array}$ & $\begin{array}{l}2518.9 \\
(808.5)\end{array}$ & $2178.2(776.7)$ \\
\hline DASH score (max. possible 10), mean (SD) & $4.82(0.9)$ & $4.13(1.0)$ & $4.48(1.0)$ \\
\hline \multicolumn{4}{|l|}{ DASH score in tertiles, $n(\%)$} \\
\hline low & $366(20.7 \%)$ & $797(45.8 \%)$ & $1163(33.1 \%)$ \\
\hline medium & $620(35.0 \%)$ & $586(33.7 \%)$ & $1206(34.3 \%)$ \\
\hline high & $786(44.4 \%)$ & $358(20.6 \%)$ & $1144(32.6 \%)$ \\
\hline MEDAS score (max. possible 14), mean (SD) & $5.16(1.7)$ & $3.91(1.7)$ & $4.54(1.8)$ \\
\hline \multicolumn{4}{|l|}{ MEDAS score in tertiles, $n(\%)$} \\
\hline low & $357(20.1 \%)$ & $827(47.5 \%)$ & $1184(33.7 \%)$ \\
\hline medium & $606(34.2 \%)$ & $563(32.3 \%)$ & $1169(33.3 \%)$ \\
\hline high & $809(45.7 \%)$ & $351(20.2 \%)$ & $1160(33.0 \%)$ \\
\hline
\end{tabular}

More women were categorized as "normal" chronotype (women: $45.6 \%$ vs. men: $42.5 \%$ ). Men more often showed a "late" chronotype (women $25.4 \%$ vs. men $29.0 \%$ ).

On average, women had a higher DASH score. Men were twice as often assigned, the "low" category of the DASH score tertile as women. The same trends applied to the MEDAS score.

Participants classified as an "early" chronotype showed the lowest daily calorie intake, and persons categorized as "late" chronotype the highest (see Table 3). "Late" chronotype 
participants showed a statistically significant lower DASH score than the other two chronotype groups. "Late" chronotype also received a "high" DASH score less often. This was not observed for the MEDAS score.

Table 3. Energy and dietary adherence score characteristics stratified after Chorotype.

\begin{tabular}{|c|c|c|c|c|c|c|}
\hline & $\begin{array}{l}\text { "Normal" } \\
(n=1548)\end{array}$ & $\begin{array}{c}\text { Early } \\
(n=1010)\end{array}$ & $\begin{array}{c}\text { Late } \\
(n=995)\end{array}$ & $\begin{array}{c}\text { Total } \\
(n=3513)\end{array}$ & $\begin{array}{l}p \text {-Value " } \\
\text { Normal" vs. } \\
\text { Early }\end{array}$ & $\begin{array}{c}p \text {-Value " } \\
\text { Normal" vs. } \\
\text { Late }\end{array}$ \\
\hline Energy intake, kcal/day, mean (SD) & $2179.5(784.1)$ & $2101.0(719.8)$ & $2257.8(814.2)$ & $2178.2(776.7)$ & $0.024(1)$ & $0.009(1)$ \\
\hline DASH score, mean (SD) & $4.53(1.1)$ & $4.50(1.0)$ & $4.37(1.1)$ & $4.48(1.0)$ & $0.552(1)$ & $<0.001(1)$ \\
\hline DASH score in tertiles, $n(\%)$ & & & & & $0.900(2)$ & $0.004(2)$ \\
\hline - low & $485(31.3 \%)$ & $325(32.2 \%)$ & $353(37.0 \%)$ & $1163(33.1 \%)$ & & \\
\hline - medium & $533(34.4 \%)$ & $345(34.2 \%)$ & $328(34.3 \%)$ & $1206(34.3 \%)$ & & \\
\hline - high & $530(34.2 \%)$ & $340(33.7 \%)$ & $274(28.7 \%)$ & $1144(32.6 \%)$ & & \\
\hline MEDAS score, mean (SD) & $4.56(1.9)$ & $4.52(1.8)$ & $4.53(1.8)$ & $4.54(1.8)$ & $0.412(1)$ & $0.492(1)$ \\
\hline MEDAS score in tertiles, $n(\%)$ & & & & & $0.248(2)$ & $0.475(2)$ \\
\hline - low & $500(32.3 \%)$ & $356(35.2 \%)$ & $328(34.3 \%)$ & $1184(33.7 \%)$ & & \\
\hline - medium & $517(33.4 \%)$ & $333(33.0 \%)$ & $319(33.4 \%)$ & $1169(33.3 \%)$ & & \\
\hline - high & $531(34.3 \%)$ & $321(31.8 \%)$ & $308(32.3 \%)$ & $1160(33.0 \%)$ & & \\
\hline
\end{tabular}

(1) Kruskal-Wallis rank-sum test; (2) Pearson's Chi-squared test.

Women were more often adipose according to the measured waist circumference (women: $73.9 \%$ vs. men: $69.2 \%$, see Table 4). Men had worse metabolic index parameters, apart from the reduced HDL, which showed no sex difference. MetS (IDF) showed 28.2\% of women and $44.2 \%$ of men.

Table 4. Characteristics of the metabolic syndrome, according to the IDF index (2005).

\begin{tabular}{|c|c|c|c|c|}
\hline & Women $(n=1772)$ & $\operatorname{Men}(n=1741)$ & Total $(n=3513)$ & $p$-Value \\
\hline $\begin{array}{c}\text { Waist circumference }(>80 \mathrm{~cm} \text { women, }>94 \mathrm{~cm} \\
\text { men), } n(\%)\end{array}$ & $1298(73.9 \%)$ & $1198(69.2 \%)$ & $2496(71.6 \%)$ & $0.002(1)$ \\
\hline Triglycerides > $150 \mathrm{mg}, n(\%)$ & $300(17.0 \%)$ & $476(27.5 \%)$ & $776(22.2 \%)$ & $<0.001(1)$ \\
\hline HDL ( $<50 \mathrm{mg} / \mathrm{dL}$ women, $<40 \mathrm{men}), n(\%)$ & $187(10.6 \%)$ & $200(11.5 \%)$ & $387(11.1 \%)$ & $0.369(1)$ \\
\hline $\begin{array}{c}\text { Blood pressure (systolic }>130 \mathrm{mmHg} \text { or diastolic } \\
\qquad>85 \mathrm{mmHg}), n(\%)\end{array}$ & $924(53.4 \%)$ & $1145(67.3 \%)$ & $2069(60.3 \%)$ & $<0.001(1)$ \\
\hline $\begin{array}{l}\text { Fasting plasma glucose }(>100 \mathrm{mg} / \mathrm{dL}) \text { or diabetes } \\
\text { mellitus, } n(\%)\end{array}$ & $305(18.4 \%)$ & $541(34.1 \%)$ & $846(26.1 \%)$ & $<0.001(1)$ \\
\hline Metabolic syndrome, $n(\%)$ & $500(28.2 \%)$ & $770(44.2 \%)$ & $1270(36.2 \%)$ & $<0.001(1)$ \\
\hline
\end{tabular}

(1) Pearson's Chi-squared test.

\subsection{Results of Logistic Regression Analyses}

Table 5 shows the logistic regression model results, including all 3513 participants. Risk factors for MetS were higher age, male sex, less than $1 \mathrm{~h}$ of sport per week, and not having a "high" school diploma. Having a "low" DASH score was a statistically significant risk factor (OR 1.23; 95\% CI 1.01-1.48). Low and medium MEDAS scores were risk factors, but none of the odds ratios statistically reached significance. Only for "late" chronotype, a slightly elevated OR (1.06) was found, but no statistically significant effect on the outcome MetS, but improved the model. 
Table 5. Multiple logistic regression. Adjusted odds ratio (OR) estimates of pre-selected independent variables to the dependent variable metabolic syndrome $(n=3513)$.

\begin{tabular}{|c|c|c|c|c|c|}
\hline Risk Factor & Category & Reference & OR & $95 \% \mathrm{CI}$ & $p$-Value \\
\hline Age & $\geq 65$ & $<65$ & 1.54 & $(1.32,1.79)$ & $<0.001$ \\
\hline Sex & men & women & 1.93 & $(1.65,2.25)$ & $<0.001$ \\
\hline School diploma & $\begin{array}{l}\text { medium } \\
\text { low }\end{array}$ & high & $\begin{array}{l}1.48 \\
2.04\end{array}$ & $\begin{array}{l}(1.24,1.75) \\
(1.68,2.49)\end{array}$ & $\begin{array}{l}<0.001 \\
<0.001\end{array}$ \\
\hline Smoking status & $\begin{array}{c}\text { ex-smoker } \\
\text { current smoker }\end{array}$ & never-smoker & $\begin{array}{l}1.29 \\
1.47\end{array}$ & $\begin{array}{l}(1.10,1.52) \\
(1.20,1.81)\end{array}$ & $\begin{array}{c}0.002 \\
<0.001\end{array}$ \\
\hline Sport/physical training & $<1 \mathrm{~h} /$ week & $\geq 1 \mathrm{~h} /$ week & 1.55 & $(1.32,1.81)$ & $<0.001$ \\
\hline Chronotype & $\begin{array}{l}\text { early } \\
\text { late }\end{array}$ & "normal" & $\begin{array}{l}0.97 \\
1.06\end{array}$ & $\begin{array}{l}(0.81,1.15) \\
(0.89,1.26)\end{array}$ & $\begin{array}{l}0.698 \\
0.522\end{array}$ \\
\hline DASH score (tertiles) & $\begin{array}{l}\text { medium } \\
\text { low }\end{array}$ & high & $\begin{array}{l}1.16 \\
1.23\end{array}$ & $\begin{array}{l}(0.97,1.40) \\
(1.01,1.48)\end{array}$ & $\begin{array}{l}0.100 \\
0.035\end{array}$ \\
\hline
\end{tabular}

Figure 1 displays the test for possible interaction between DASH and chronotype. Whereas within the "low" DASH score category, a trend of increasing risk of MetS from normal via early to late chronotype can be observed, the categories of high and moderate adherence to DASH diet showed no trend.

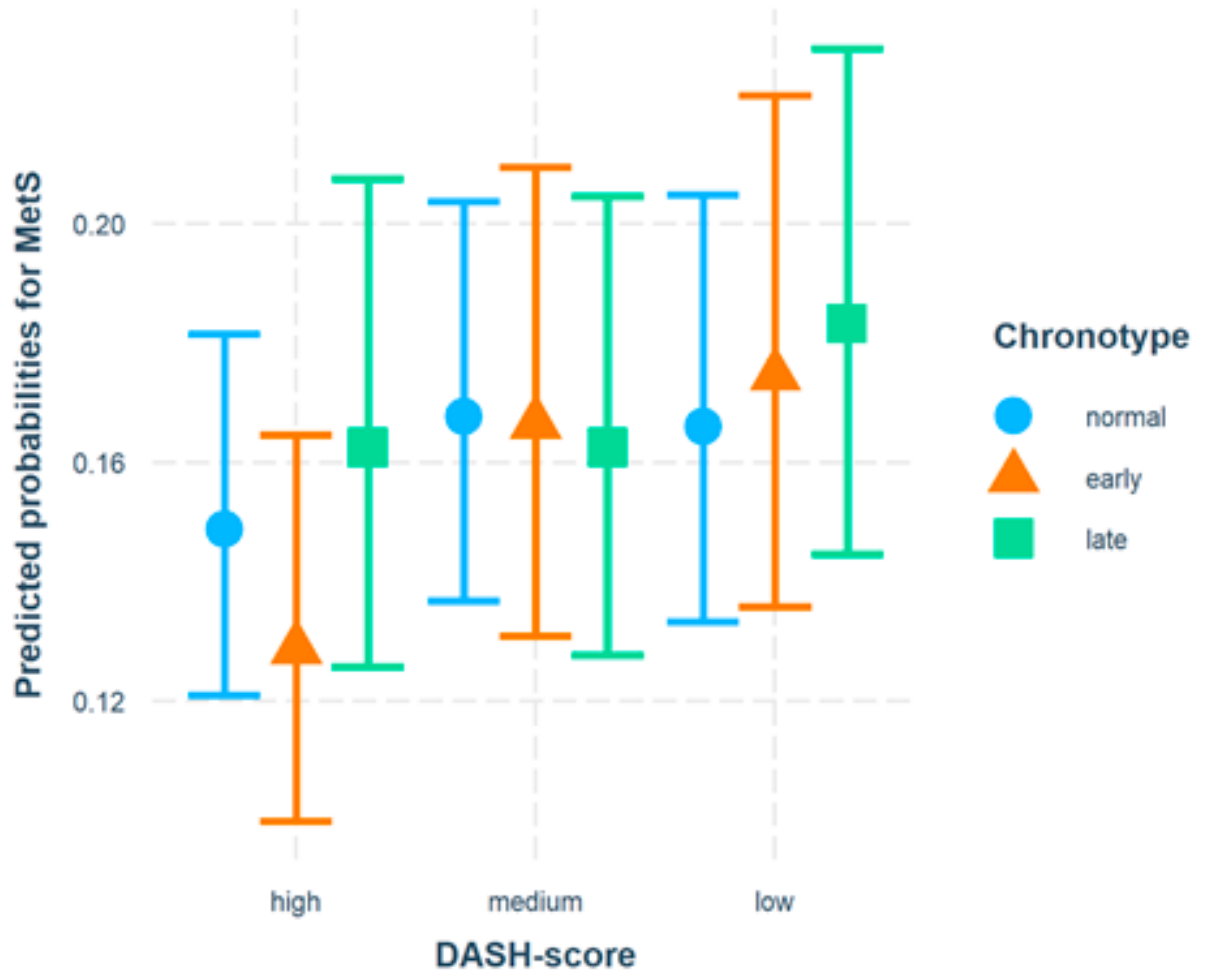

Figure 1. Multiple logistic regression with an interaction term between DASH score and chronotype with metabolic syndrome (MetS) as a dependent variable. Adjusted for age, sex, sport, school diploma, and smoking status $(n=3513)$.

\section{Discussion}

In this cross-sectional study, we investigated the association between chronotype, dietary quality, and the prevalence of the MetS in an elderly population-based cohort, considering age, sex, education, and further relevant lifestyle factors. Overall, we found that women had a higher DASH score, whereas men were twice as often assigned the "low" DASH category. The same was found in an analysis of periodontitis [22]. Higher adherence 
to the DASH or the MEDAS diet was associated with less conventional cardiovascular risk factors and the prevalence of MetS. Participants assigned to the "late" chronotype were more often characterized by higher energy intake and a lower DASH score. In a logistic regression analysis, age, male sex, less than $1 \mathrm{~h}$ of sport per week, not having a high school diploma, and being categorized to the low DASH score were independent risk factors for the MetS, while the chronotype vastly improved the model but failed to show significance.

In this elderly population from the HCHS study, the prevalence of MetS was higher in men than women (men: $44.2 \%$ vs. women: $28.2 \%$, see Table 4 ). Our observation that males were particularly characterized by a cluster of metabolic risk factors, including higher blood pressure values, impaired glucose metabolism, and raised triglycerides is consistent with German nationwide research [4,5]. However, more women than men presented with central obesity despite lower mean BMI. This finding can be explained predominantly by hormonal and metabolic changes that occur during the menopause transition. Actually, estrogen loss adversely alters body fat distribution, cholesterol profile, blood pressure, and increased insulin resistance [23].

Central obesity independent of BMI is the key factor in the development of MetS. Besides hereditable determinants, modifying lifestyle factors such as dietary habits, physical activity, and to a certain extent, smoking status, remain the major driving force [24]). Overall, elderly women in HCHS followed a favorable lifestyle compared to men. Significantly more women described themselves as never smokers, as physically active $(\geq 1 \mathrm{~h}$ sports/week), and reported higher adherence to both healthy dietary patterns, DASH and MEDAS. More than twice as many women as men were assigned to the highest tertile of DASH and the MEDAS score. Sex-specific differences in health behavior, particularly dietary habits and related risk factors, are well-known among adult populations [25,26]. Although mean adherence to the DASH score was underparts (4.48 of 10) in the study population, it was significantly higher in the older age group (65-74 yr) compared to younger participants (50-64 yr). A healthier food choice with increasing age has been described elsewhere [27].

As expected from previous research, adherence to the DASH diet seemed to be cardioprotective $[7,23]$. The prevalence of conventional cardiovascular risk factors was slightly but significantly lower in the highest tertile compared to the lowest. This includes central obesity (68.6\% vs. $71.6 \%$ ), elevated blood pressure (56\% vs. $64.9 \%)$, diabetes (21.7\% vs. $29.6 \%)$, raised triglycerides (16.4\% vs. $28 \%$ ) and low HDL-cholesterol (8.1\% vs. $13.4 \%)$. The same trend applied to the MEDAS diet. Consequently, high adherence to both diets was associated with a lower prevalence of MetS (DASH: 29.6\% vs. 42.1\%; MEDAS: $29.2 \%$ vs. $41.7 \%)$.

In this analysis, individual chronotype was referable for 3513 participants (women: $n=1772$; men: 1741). Chronotype was classified as "normal" in $44.1 \%$ of the participants, "early" in $28.8 \%$, and "late" in $27.2 \%$. Almost equally in men and women, one-third was classified as "early" chronotype (28.5\% vs. $29.0 \%$ ). More men than women were classified as "late" chronotype (men: $29.0 \%$ vs. women: $25.4 \%$ ). This finding is consistent with a meta-analysis of Randler and Engelke (2019), which included 164 studies. Randler and Engelke also observed that gender differences diminish with age, but still, older women were less often early chronotype than older men [28] - a result not found in our sample.

Growing evidence indicates the contribution of chronotype to central obesity [24]. A scoping review of Mazri et al. (2020) concluded that the late chronotype is associated with a delay in meal timing, skipping breakfast, and more meals during nighttime, together with higher consumption of sweets, caffeine, and alcohol [13]. Morning and evening types were relatively alike in consuming carbohydrates, fat, cholesterol, fiber, legumes, meat, fish, or dairy products. Chronotype has often been linked to dietary intake. Individuals with "late" chronotype particularly follow an unhealthier dietary behavior $[10,13,23,29]$. These studies are largely supportive of our findings. Participants classified as "late" chronotypes showed the highest energy intake, statistically significant, compared to those with a "normal" chronotype. Additionally, "late" chronotypes belong less often to the higher DASH score 
category and were characterized by a significantly lower DASH score in contrast to the other two chronotypes. Differences between chronotype and the MEDAS score failed to show significance. The lack of association is likely due to the overall low adherence to the MEDAS score (mean: 4.54 points out of max possible 14 points) in this aging, nonMediterranean population. For example, less than $5 \%$ of the participants fulfilled key diet components, such as the intake of olive oil, fish/seafood, red meat and pulses. Thus, even those in the highest tertile did not eat in accordance with the recommendations.

Depending on the completeness of data to classify chronotype, 3513 participants were included in the multiple logistic regression model. As expected being male (OR $=1.93 ; 95 \%$ CI 1.93-2.25), 65 years or older (OR $=1.54 ; 95 \%$ CI 1.32-1.79) and a low educational level $(\mathrm{OR}=2.04 ; 95 \%$ CI 1.68-2.49) stand for statistically significant elevated risks for MetS.

Physical activity is known to be important in the prevention and as an intervention for MetS [6,30]. According to this, our analysis showed "less than $1 \mathrm{~h}$ of sport per week" as a risk factor $(\mathrm{OR}=1.55 ; 95 \% \mathrm{CI} 1.32-1.81)$.

Less impact was found for the DASH diet in this elderly cohort. Only for participants with low adherence, the elevated risk of MetS became statistically significant $(\mathrm{OR}=1.23 ; 95 \%$ CI 1.01-1.48). In a review of Filippou et al. (2020), it was found that in trials investigating the DASH diet with mean age $<50$-years, blood pressure was reduced more, so our findings are plausible in this context [31].

Chronotype was not directly associated with MetS, neither "early" nor "late." A slightly elevated OR (1.06) was observed for late chronotype but not statistically significant. That was why we tested for a possible interaction between the DASH diet and chronotype (Figure 1). For participants with low adherence to the DASH diet, a trend of an increasing predicted probability from early to late chronotype was found. Such a trend was not clear in the DASH categories with medium or high scores. It might be concluded that a combination of late chronotype and low DASH score possibly increased the risk of developing a MetS.

Our findings will add to the limited number of studies investigating the association between chronotype, dietary quality, and MetS in an elderly population-based cohort, considering age, sex, and education as well as physical activity and smoking status. Chronotype and dietary and lifestyle habits were assessed by validated methods/instruments. However, a cross-sectional design can not reveal causality, and information on chronotype, diet, and lifestyle behavior were based only on self-reported data. In this data analysis based on the first 10,000 participants, health-conscious individuals were more likely to participate in the investigation, which we observed referring to the level of education and proportion of current smokers or adipose persons [32], respectively. Therefore, reporting and selection bias can not be excluded.

\section{Conclusions}

In total, the data showed that in HCHS, known risk factors for MetS are confirmed. However, lifestyle factors like smoking or lack of exercise are contributing less than low education.

Participants of this northern German HCHS cohort investigated here are quite similar in diet adherence related to the prevention of hypertension. Men and women score close around four underparts with a small standard deviation for DASH adherence. But only those attributed to the lowest tertile of the DASH score we observed to be at risk of MetS. Within this group, late chronotype was found to be an unfavorable condition.

Future research should focus on options for prevention in persons with late chronotype, so they can be supported better in adherence to, e.g., DASH diet to lower their risk.

Author Contributions: Conceptualization, C.T. and B.-C.Z.; methodology, C.T. and B.-C.Z.; formal analysis, L.D. and E.L.P.; data curation, E.L.P. and L.D.; writing-original draft preparation, C.T., B.-C.Z. and L.D.; writing-review and editing, C.T. and B.-C.Z.; visualization, L.D.; supervision, V.H. and M.A.; funding acquisition, V.H., M.A. and B.-C.Z. All authors have read and agreed to the published version of the manuscript. 
Funding: This research received no external funding.

Institutional Review Board Statement: The study was conducted according to the guidelines of the Declaration of Helsinki and approved by the Data Protection Commissioner of the UNIVERSITY MEDICAL CENTER OF THE UNIVERSITY HAMBURG-EPPENDORF (NCT number 03934957) and by the ethical committee of the Medical Association of Hamburg, Germany (PV5131).

Informed Consent Statement: Informed consent was obtained from all subjects involved in the study.

Data Availability Statement: Due to the nature of this research, participants of this study did not agree for their data to be shared publicly, so supporting data is not available.

Acknowledgments: We thank all participants of the HCHS for attendance and the data management of the Hamburg City Health Study for their support and cooperation.

Conflicts of Interest: The authors declare no conflict of interest.

\section{Appendix A}

Table A1. Scoring criteria for Mediterranean Dietary score.

\begin{tabular}{|c|c|c|}
\hline Score Item & MEDAS Question & $\begin{array}{l}\text { Data Recorded by FFQ } \\
1 \text { Point Given, if ... }\end{array}$ \\
\hline 1 & $\begin{array}{l}\text { Do you use olive oil as the principal source of fat } \\
\text { for cooking? }\end{array}$ & $\begin{array}{l}\text { use of olive oil for the preparation of at least } 2 \text { of the } \\
\text { following groceries: salad, vegetable, meat/fish }\end{array}$ \\
\hline 2 & $\begin{array}{l}\text { How much olive oil do you consume per day (including } \\
\text { that used in frying, salads, meals eaten away from } \\
\text { home, etc.)? }\end{array}$ & $\begin{array}{c}\text { based on FFQ calculation, if }>48 \text { g vegetable oil } \\
\text { per day }\end{array}$ \\
\hline 3 & $\begin{array}{l}\text { How many servings of vegetables do you consume } \\
\text { per day? }\end{array}$ & $\begin{array}{c}\text { based on FFQ calculation, if } \geq 2 \text { portions of vegetables } \\
\text { per day (including raw and cooked vegetables, salad, } \\
\text { olives, mushrooms except potatoes and legumes) }\end{array}$ \\
\hline 4 & $\begin{array}{l}\text { How many pieces of fruit (including fresh-squeezed juice) } \\
\text { do you consume per day? }\end{array}$ & $\begin{array}{l}\text { based on FFQ calculation, if } \geq 3 \text { portions of fruit } \\
\text { (including fruit, mixed fruit, fruit salad, mixed stewed } \\
\text { fruit and fruit juices excluding sweetened beverages) }\end{array}$ \\
\hline 5 & $\begin{array}{l}\text { How many servings of red meat, hamburger, or sausages } \\
\text { do you consume per day? }\end{array}$ & $\begin{array}{l}\text { based on FFQ calculation, if }<100 \text { g red meat (eg beef, } \\
\text { veal, pork, lamb) and processed meat products }\end{array}$ \\
\hline 6 & $\begin{array}{l}\text { How many servings ( } 12 \mathrm{~g} \text { ) of butter, margarine, or cream } \\
\text { do you consume per day? }\end{array}$ & $\begin{array}{l}\text { based on FFQ calculation, if }<1 \text { portion butter, } \\
\text { margarine and cream and other animal fat }\end{array}$ \\
\hline 7 & $\begin{array}{c}\text { How many carbonated and/or sugar-sweetened } \\
\text { beverages do you consume per day? }\end{array}$ & $\begin{array}{l}\text { based on FFQ calculation, sugar-sweetened beverages } \\
<1 \text { portion per day (including lemonade and colas) }\end{array}$ \\
\hline 8 & $\begin{array}{l}\text { Do you drink wine? How much do you consume } \\
\text { per week? }\end{array}$ & $\begin{array}{l}\text { based on FFQ calculation, if } \geq 7 \text { portions wine (red } \\
\text { and white wine; } 1 \text { portion }=0.251 \text { ) }\end{array}$ \\
\hline 9 & How many servings of pulses do you consume per week? & $\begin{array}{c}\geq 3 \text { portions pulses (e.g., beans, lentils, peas, } \\
\text { chickpeas) }\end{array}$ \\
\hline 10 & $\begin{array}{l}\text { How many servings of fish/seafood do you consume } \\
\text { per week? }\end{array}$ & $\begin{array}{c}\text { based on FFQ calculation, if } \geq 3 \text { portions fish, fish } \\
\text { products and seafood per week }\end{array}$ \\
\hline 11 & $\begin{array}{l}\text { How many times do you consume commercial (not } \\
\text { homemade)pastry such as cookies or cake per week? }\end{array}$ & $\begin{array}{c}\text { based on FFQ calculation, if }<3 \text { portions cakes, } \\
\text { chocolate, cookies, sweets with and without chocolate } \\
\text { per week }\end{array}$ \\
\hline 12 & How many times do you consume nuts per week? & based on FFQ calculation, if $\geq 3$ portions nuts per week \\
\hline 13 & $\begin{array}{l}\text { Do you prefer to eat chicken, turkey or rabbit instead of } \\
\text { beef, pork, hamburgers, or sausages? }\end{array}$ & $\begin{array}{l}\text { Based on FFQ calculation, if g white meat (e.g., } \\
\text { chicken, hen and other poultry) > g red meat (e.g., } \\
\text { beef, veal, pork, lamb and processed meat products) }\end{array}$ \\
\hline 14 & $\begin{array}{l}\text { How many times per week do you consume boiled } \\
\text { vegetables, pasta, rice, or other dishes with a sauce of } \\
\text { tomato, garlic, onion, or leeks sautéed in olive oil? }\end{array}$ & $>1-2$ times a week tomato sauce \\
\hline
\end{tabular}




\section{References}

1. Alberti, K.G.M.M.; Zimmet, P.; Shaw, J.; IDF Epidemiology Task Force Consensus Group. The metabolic syndrome-A new worldwide definition. Lancet 2005, 366, 1059-1062. [CrossRef]

2. Sundström, J.; Lind, L.; Lampa, E.; Angerås, O.; Bachus, E.; Bergström, G.; Carlberg, B.; Engström, G.; Engvall, J.E.; Eriksson, M.; et al. Weight gain and blood pressure. J. Hypertens. 2020, 38, 387-394. [CrossRef]

3. Schipf, S.; Alte, D.; Völzke, H.; Friedrich, N.; Haring, R.; Lohmann, T.; Rathmann, W.; Nauck, M.; Felix, S.; Hoffmann, W.; et al. Prävalenz des Metabolischen Syndroms in Deutschland: Ergebnisse der Study of Health in Pomerania (SHIP). Diabetol. Stoffwechs. 2010, 5, 161-168. [CrossRef]

4. Heidemann, C.; Kuhnert, R.; Born, S.; Scheidt-Nave, C. 12-Monats-Prävalenz des bekannten Diabetes mellitus in Deutschland. J. Health Monit. 2017, 2, 48-56. [CrossRef]

5. Neuhauser, H.; Kuhnert, R.; Born, S. 12-Monats-Prävalenz von Bluthochdruck in Deutschland. J. Health Monit. 2017, 2, 57-63. [CrossRef]

6. Myers, J.; Kokkinos, P.; Nyelin, E. Physical Activity, Cardiorespiratory Fitness, and the Metabolic Syndrome. Nutrients 2019, 11, 1652. [CrossRef] [PubMed]

7. Castro-Barquero, S.; Ruiz-León, A.M.; Sierra-Pérez, M.; Estruch, R.; Casas, R. Dietary Strategies for Metabolic Syndrome: A Comprehensive Review. Nutrients 2020, 12, 2983. [CrossRef] [PubMed]

8. Almoosawi, S.; Vingeliene, S.; Gachon, F.; Voortman, T.; Palla, L.; Johnston, J.; Van Dam, R.M.; Darimont, C.; Karagounis, L.G. Chronotype: Implications for Epidemiologic Studies on Chrono-Nutrition and Cardiometabolic Health. Adv. Nutr. 2018, 10, 30-42. [CrossRef] [PubMed]

9. Suh, S.; Yang, H.-C.; Kim, N.; Yu, J.H.; Choi, S.; Yun, C.-H.; Shin, C. Chronotype Differences in Health Behaviors and HealthRelated Quality of Life: A Population-Based Study Among Aged and Older Adults. Behav. Sleep Med. 2016, 15, 361-376. [CrossRef] [PubMed]

10. Maukonen, M.; Kanerva, N.; Partonen, T.; Kronholm, E.; Konttinen, H.; Wennman, H.; Männistö, S. The associations between chronotype, a healthy diet and obesity. Chronobiol. Int. 2016, 33, 972-981. [CrossRef]

11. Kanerva, N.; Kronholm, E.; Partonen, T.; Ovaskainen, M.-L.; Kaartinen, N.E.; Konttinen, H.; Broms, U.; Männistö, S. Tendency toward Eveningness Is Associated with Unhealthy Dietary Habits. Chronobiol. Int. 2012, 29, 920-927. [CrossRef] [PubMed]

12. Patterson, F.; Malone, S.K.; Lozano, A.; Grandner, M.; Hanlon, A.L. Smoking, Screen-Based Sedentary Behavior, and Diet Associated with Habitual Sleep Duration and Chronotype: Data from the UK Biobank. Ann. Behav. Med. 2016, 50, 715-726. [CrossRef]

13. Mazri, F.H.; Manaf, Z.A.; Shahar, S.; Ludin, A.F.M. The Association between Chronotype and Dietary Pattern among Adults: A Scoping Review. Int. J. Environ. Res. Public Health 2019, 17, 68. [CrossRef]

14. Roenneberg, T.; Allebrandt, K.V.; Merrow, M.; Vetter, C. Social Jetlag and Obesity. Curr. Biol. 2012, 22, 939-943. [CrossRef]

15. Jagodzinski, A.; Johansen, C.; Koch-Gromus, U.; Aarabi, G.; Adam, G.; Anders, S.; Augustin, M.; Der Kellen, R.B.; Beikler, T.; Behrendt, C.-A.; et al. Rationale and Design of the Hamburg City Health Study. Eur. J. Epidemiol. 2019, 35, 169-181. [CrossRef]

16. Nöthlings, U.; Hoffmann, K.; Bergmann, M.M.; Boeing, H. Fitting Portion Sizes in a Self-Administered Food Frequency Questionnaire. J. Nutr. 2007, 137, 2781-2786. [CrossRef]

17. Folsom, A.R.; Parker, E.; Harnack, L.J. Degree of Concordance With DASH Diet Guidelines and Incidence of Hypertension and Fatal Cardiovascular Disease. Am. J. Hypertens. 2007, 20, 225-232. [CrossRef] [PubMed]

18. Epstein, D.E.; Sherwood, A.; Smith, P.J.; Craighead, L.; Caccia, C.; Lin, P.-H.; Babyak, M.A.; Johnson, J.J.; Hinderliter, A.; Blumenthal, J.A. Determinants and Consequences of Adherence to the Dietary Approaches to Stop Hypertension Diet in AfricanAmerican and White Adults with High Blood Pressure: Results from the ENCORE Trial. J. Acad. Nutr. Diet. 2012, 112, $1763-1773$. [CrossRef] [PubMed]

19. Hebestreit, K.; Yahiaoui-Doktor, M.; Engel, C.; Vetter, W.; Siniatchkin, M.; Erickson, N.; Halle, M.; Kiechle, M.; Bischoff, S.C. Validation of the German version of the Mediterranean Diet Adherence Screener (MEDAS) questionnaire. BMC Cancer 2017, 17, 341. [CrossRef]

20. Roenneberg, T.; Wirz-Justice, A.; Merrow, M. Life between Clocks: Daily Temporal Patterns of Human Chronotypes. J. Biol. Rhythm. 2003, 18, 80-90. [CrossRef]

21. Wareham, N.J.; Jakes, R.W.; Rennie, K.L.; Mitchell, J.; Hennings, S.; Day, N.E. Validity and repeatability of the EPIC-Norfolk Physical Activity Questionnaire. Int. J. Epidemiol. 2002, 31, 168-174. [CrossRef]

22. Altun, E.; Walther, C.; Borof, K.; Petersen, E.; Lieske, B.; Kasapoudis, D.; Jalilvand, N.; Beikler, T.; Jagemann, B.; Zyriax, B.-C.; et al Association between Dietary Pattern and Periodontitis-A Cross-Sectional Study. Nutrients 2021, 13, 4167. [CrossRef] [PubMed]

23. Munshi, A.; Desai, S.; Munshi, D. Gender bias in cardiovascular disease prevention, detection, and management, with specific reference to coronary artery disease. J. Mid-Life Health 2021, 12, 8-15. [CrossRef]

24. De Amicis, R.; Galasso, L.; Leone, A.; Vignati, L.; De Carlo, G.; Foppiani, A.; Montaruli, A.; Roveda, E.; Ce, E.; Esposito, F.; et al. Is Abdominal Fat Distribution Associated with Chronotype in Adults Independently of Lifestyle Factors? Nutrients 2020, 12, 592. [CrossRef] [PubMed]

25. Zyriax, B.C.; Lau, K.; Klahn, T.; Boeing, H.; Volzke, H.; Windler, E. Association between alcohol consumption and carotid intima-media thickness in a healthy population: Data of the STRATEGY study (Stress, Atherosclerosis and ECG Study). Eur. J. Clin. Nutr. 2010, 64, 1199-1206. [CrossRef] [PubMed] 
26. Zyriax, B.-C.; Dransfeld, K.; Windler, E. Carotid intima-media thickness and cardiovascular risk factors in healthy volunteers. Ultrasound J. 2021, 13, 17. [CrossRef]

27. Pot, G.K.; Teams, T.N.S.A.D.C.; Prynne, C.J.; Almoosawi, S.; Kuh, D.; Stephen, A.M. Trends in food consumption over 30 years: Evidence from a British birth cohort. Eur. J. Clin. Nutr. 2014, 69, 817-823. [CrossRef]

28. Randler, C.; Engelke, J. Gender differences in chronotype diminish with age: A meta-analysis based on morningness/chronotype questionnaires. Chronobiol. Int. 2019, 36, 888-905. [CrossRef]

29. Muscogiuri, G.; Barrea, L.; Aprano, S.; Framondi, L.; Di Matteo, R.; Altieri, B.; Laudisio, D.; Pugliese, G.; Savastano, S.; Colao, A. Chronotype and cardio metabolic health in obesity: Does nutrition matter? Int. J. Food Sci. Nutr. 2021, 72, 892-900. [CrossRef]

30. Pérez-Martínez, P.; Mikhailidis, D.P.; Athyros, V.G.; Bullo, M.; Couture, P.; Covas, M.I.; de Koning, L.; Delgado-Lista, J.; DíazLópez, A.; Drevon, C.A.; et al. Lifestyle recommendations for the prevention and management of metabolic syndrome: An international panel recommendation. Nutr. Rev. 2017, 75, 307-326. [CrossRef]

31. Filippou, C.D.; Tsioufis, C.P.; Thomopoulos, C.G.; Mihas, C.C.; Dimitriadis, K.S.; Sotiropoulou, L.I.; Chrysochoou, C.A.; Nihoyannopoulos, P.I.; Tousoulis, D.M. Dietary Approaches to Stop Hypertension (DASH) Diet and Blood Pressure Reduction in Adults with and without Hypertension: A Systematic Review and Meta-Analysis of Randomized Controlled Trials. Adv. Nutr. 2020, 11, 1150-1160. [CrossRef] [PubMed]

32. Mensink, G.B.; Schienkiewitz, A.; Haftenberger, M.; Lampert, T.; Ziese, T.; Scheidt-Nave, C. Overweight and obesity in Germany: Results of the German Health Interview and Examination Survey for Adults (DEGS1). Bundesgesundheitsblatt -Gesundh. -Gesundh. 2013, 56, 786-794. [CrossRef] [PubMed] 